\title{
RED
}

MARKA

Revista de Marketing Aplicado

Vol. 23, núm. 3 (2019), 29-45

ISSN: $1852-2300$

Recibido el 5 de diciembre de 2019

DOI: https://doi.org/10.17979/redma.2019.23.3.5875

Aceptado el 24 de diciembre de 2019

\section{La imagen de los candidatos en las Elecciones Generales de 2019 en España}

The image of the candidates in the 2019 General Elections in Spain

\author{
Yolanda Cabrera García-Ochoa \\ Universidad de Valencia \\ Germán Llorca-Abad \\ Universidad de Valencia
}

\section{Resumen}

Las Elecciones Generales de 1977 en España obligaron a los partidos a explicar cuestiones elementales como "qué significaba votar". En general, la imagen proyectada de los candidatos era una cuestión "menor", dada la falta de cultura democrática del momento. Tras 42 años desde la transición, el contexto político y comunicativo ha dado un vuelco que exige de una aproximación más compleja.

Los partidos políticos son conscientes de la importancia que tiene construir la imagen pública de sus candidatos. En este trabajo analizamos la imagen del principal cartel de campaña de los candidatos a presidente en las Elecciones Generales de abril de 2019

Cabrera García-Ochoa, Yolanda, https://orcid.org/0000-0003-1584-3695, Universidad de Valencia, yolanda.cabrera@uv.es

Llorca-Abad, Germán, https://orcid.org/0000-0002-0934-8420, Universidad de Valencia, german.llorca@uv.es

Forma de citar este artículo: Cabrera García-Ochoa, Y., \& Llorca-Abad, G. (2019). La imagen de los candidatos en las Elecciones Generales de 2019 en España, Redmarka. Revista de Marketing Aplicado, vol 23, núm. 3, 29-45. https://doi.org/10.17979/redma.2019.23.3.5875 
de Vox, PP, C's, PSOE, UP y del candidato al Congreso de IU. El objetivo del trabajo es demostrar, mediante un análisis semiótico y de contenido, la relación existente entre la imagen de la persona candidata con los valores de identidad ideológica que se le atribuyen.

Palabras clave: comunicación política, esfera publica emocional, elecciones generales, campaña electoral, tecnologías de la comunicación

\section{Abstract}

The 1977 General Elections in Spain forced political parties to explain elementary questions such as "what it meant to vote". In general terms, the projected image of the candidates was a "minor" issue, given the lack of democratic culture at the time. After 42 years after transition, the political and communicative context has changed, demanding a more complex approach.

Political parties are aware of the importance of building the public image of their candidates. In this work we analyse specifically the image of the main campaign poster that the candidates running for President in the 2019 General Elections of Vox, PP, C's, PSOE, UP and the running Congress' candidate for IU used. The objective of the work is to demonstrate, through a semiotic and content analysis, the relationship between the image of the candidate with the identity ideological values attributed to him.

Keywords: political communication, emotional public sphere, general elections, electoral campaign, communication technologies.

\section{INTRODUCCIÓN}

La comunicación política ha sufrido un profundo proceso de transformación en los últimos años. La emergencia de las redes digitales de comunicación ha introducido un mayor grado de complejidad desde el punto de vista del acercamiento a la ciudadanía. Las audiencias y los públicos están más fragmentados y el contexto tecnológico se transforma tan rápidamente, que resulta complicado establecer líneas estables de trabajo.

Paralelamente, el contexto político también se ha visto profundamente modificado en las últimas dos décadas. Sin duda, se trata de una transformación en el ámbito de procesos económicos, culturales y sociales globales que merecerían un análisis más pormenorizado de lo que permiten los límites de este trabajo.

Dada esta situación general, los partidos políticos son conscientes de la importancia que tiene construir la imagen pública de sus candidatos. Una parte significativa de dicha construcción se sostiene sobre la difusión de imágenes emblemáticas de los mismos en 
diferentes situaciones comunicativas. El objetivo es seducir a los posibles votantes y alcanzarlos allí donde se encuentren en las esferas comunicativas.

Durante 2019, en España se han celebrado dos elecciones generales. En este trabajo hemos analizado una selección de las imágenes que los candidatos a presidente en las Elecciones Generales de abril de 2019 de Vox, PP, C's, PSOE, UP y del candidato al Congreso de IU utilizaron durante la campaña. En concreto, la imagen del principal cartel de campaña. Este elemento, presente en todos los comicios desde la restauración de la democracia en España, ha recuperado cierto protagonismo perdido.

El objetivo del trabajo es demostrar, mediante un análisis semiótico y de contenido, la relación existente entre la imagen de la persona candidata con los atributos y valores de identidad ideológica que se le atribuyen. El análisis, delimitará la relación entre la identidad de la marca-candidato-partido y los elementos usados en su construcción.

\section{MARCO TEÓRICO}

Advertíamos en la introducción, que el contexto de la comunicación política ha cambiado profundamente en los últimos años. Esta transformación remite, al menos, a dos aspectos fundamentales. Por un lado, ha cambiado el denominado "régimen mediático" (Delli Caprini y Williams, 2011) y, por otro lado, el "régimen emocional" de la comunicación política (Peris-Blanes y Llorca-Abad, 2018). En otras palabras, el mensaje político debe ser gestionado hacia los diferentes públicos a través de un número mayor de canales y, en dicha gestión, cada vez pesa más la instrumentalización de las emociones.

Esta era de complejidad está condicionada por diversos factores, tales como el debilitamiento de las líneas que separaban a los productores de los consumidores de información, la equiparación entre hechos y opiniones, la confusión entre lo público y lo privado $y$, en especial, la desaparición de la distinción entre información y entretenimiento (Delli Caprini y Williams, 2011).

Puede afirmarse que se ha producido un desplazamiento del espacio político público hacia el terreno de lo personal. La confusión entre la esfera de la discusión pública y la esfera de lo privado es lo que algunos autores (Richards, 2010) han definido como “esfera pública emocional". En el terreno de la comunicación política, la gestión de la imagen de los candidatos se deja influir por estrategias otrora vinculadas exclusivamente a la comunicación de marketing y de las relaciones públicas. La imagen del candidato se aproxima, cada vez más, a una imagen-marca.

Es conocido que las marcas compiten entre ellas mediante la gestión comunicativa de una serie de atributos significantes. Dichos atributos sirven para definir la identidad corporativa del objeto comunicado. "La Identidad Corporativa sería el conjunto de características, valores y creencias con las que [...] se autoidentifica y se autodiferencia" (Capriotti, 2013: 141). Una vez definida la identidad, la gestión comunicativa debe de 
estar orientada al posicionamiento de una imagen positiva del objeto en la mente del receptor. En una sociedad "sobrecomunicada" como la nuestra, posicionamiento consiste "en aceptar que las percepciones son reales y, luego, reestructurarlas para crear la posición que uno desea" (Ries y Trout, 2002: 10).

Según Capriotti (2013: 29), la "imagen corporativa es un concepto basado claramente en la idea de recepción", es decir, es el resultado del proceso mental que el receptor hace de un estímulo visual. La interpretación positiva o negativa que el receptor hace, depende de su relación con lo representado por el estímulo visual, por lo que los atributos que le otorga desempeñarán un papel central o periférico en función de diversos factores (Capriotti, 2012: 62 y ss.). De entre dichos factores, destaca la reestructuración, o gestión activa de la comunicación, vista en el texto de Ries y Trout. Las nuevas reglas de la comunicación política "todavía no se han fijado y consolidado suficientemente" (Peris-Blanes y Llorca-Abad, 2018: 324), pero se advierte en el proceso una voluntad por llevarla a todos los espacios comunicación posibles. En tanto que elemento inseparable de las campañas electorales, el "cartel", cuya "pegada" da comienzo simbólico a las mismas, ha recuperado parte de la importancia perdida dentro del proceso electoral. Vico y Lepe (2019: 298) han destacado la capacidad del cartel ejercer su función "ayudando a que ideas abstractas se vuelvan comprensibles, y trabajando, por lo general, a partir de una asociación de signos gráficos apoyados en el uso de lo iconográfico y reforzados por un mensaje escrito, comúnmente una frase breve y directa llamada eslogan".

Esta función pone en valor los atributos significantes que el partido pretende asociar a su candidato-marca, con el fin de comunicarla al electorado. "El cartel de propaganda política en su sentido amplio consiste en la sistemática difusión -o transmisión- de determinadas ideas, doctrinas y prácticas de carácter político o ideológico" (Vico y Lepe, 2019: 298). El diseño y la utilización de elementos simbólicos servirá para construir la representación visual de los valores de la marca.

\section{METODOLOGÍA}

Tal y como hemos indicado, en este trabajo hemos decidido analizar una selección de las imágenes que los candidatos a presidente en las Elecciones Generales de 2019 de Vox, PP, C's, PSOE, UP y del candidato al Congreso por IU utilizaron durante la campaña electoral. En concreto, tal y como hemos tratado de justificar, la imagen principal empleada es la del cartel de campaña. Este elemento ejerce también un papel de centralidad respecto a otros carteles utilizados durante la misma.

Con este fin, hemos diseñado un análisis semiótico y de contenido haciendo una adaptación profunda de la categorización hecha por Vico y Lepe (2019). La selección de los carteles se llevó a cabo teniendo como criterios de selección la representación que obtuvo el candidato/partido una vez pasadas las elecciones y que la candidatura 
estuviera presente en, al menos, un $80 \%$ del territorio nacional. La finalidad de este planteamiento es demostrar la relación existente entre la imagen de la persona candidata con los atributos y valores de identidad ideológica que se le atribuyen. Como es sabido, Unidas Podemos e Izquierda Unida concurrieron en coalición a los comicios. No obstante, con el fin de preservar la pluralidad del análisis, las hemos mantenido separadas en este trabajo.

En la confección de la herramienta de análisis, hemos tenido en cuenta también una perspectiva multimodal (Kress y Van Leeuwen: 2006), en este caso adaptada siempre a la imagen estática. Entendemos que la validez de esta propuesta radica en el interés que ha suscitado esta herramienta analítica en los últimos años. Tal y como ha destacado Cárcamo (2018: 147) este interés "se puede asociar con los cambios en las condiciones de producción, diseminación y recepción de estos textos", es decir, con aquella "era de la complejidad" a la que aludíamos líneas atrás.

\section{RESULTADOS}

Desde que el 12 de abril de 2019 arrancase la campaña electoral con la tradicional pegada de carteles, muchas han sido las estrategias mediáticas y comunicativas llevadas a cabo por los diferentes partidos para llamar la atención del electorado. Analizamos aquí los carteles electorales como un elemento central que sirve para resumir de manera icónica y gráfica el leitmotiv que va a definir el argumentario y los ejes de campaña de cada uno de los partidos concurrentes. Además, se convierte, durante los 15 días que dura la campaña, en una especie de tapiz que invade el espacio público y privado y sirve como punto de enganche con los ciudadanos.

La tabla 1 nos permite, a modo de resumen, encontrar los puntos en común en el planteamiento de algunas propuestas, los elementos distintivos y las diferentes estrategias comunicativas y publicitarias adoptadas por cada uno de los gabinetes de campaña para transmitir una determinada imagen del partido a través de la figura del líder, o analizar la ausencia de él.

\subsection{Partido socialista}

Encontramos en el cartel utilizado por Pedro Sánchez, una adaptación con muchas similitudes a la contraportada del libro autobiográfico del líder socialista, presentado meses atrás "Manual de resistencia" un primerísimo primer plano que corta la cabeza del candidato a la altura del mentón, es un plano muy arriesgado en cinematografía y que pocos actores soportan con elegancia frente a la cámara. Pedro Sánchez tiene telegenia, sabe posar y explota aquí su atractivo físico mirando al frente, con un gesto a medio camino entre una leve sonrisa o una mueca que refleja cierto desdén, mostrándose seguro y confiado. Parte de una posición favorable, es el presidente en funciones y ha convocado él las elecciones, con unos plazos ajustados para algunos de 
sus rivales. Ese encuadre tan centrado en el rostro esconde una corbata, que aunque se intuye, no se ve. De esta manera cada espectador puede hacer una interpretación libre adaptando el código de vestimenta para sentirlo más cercano o formal y adecuarlo a sus preferencias de estilo.

Figura 1. Cartel oficial del PSOE (fuente: PSOE)

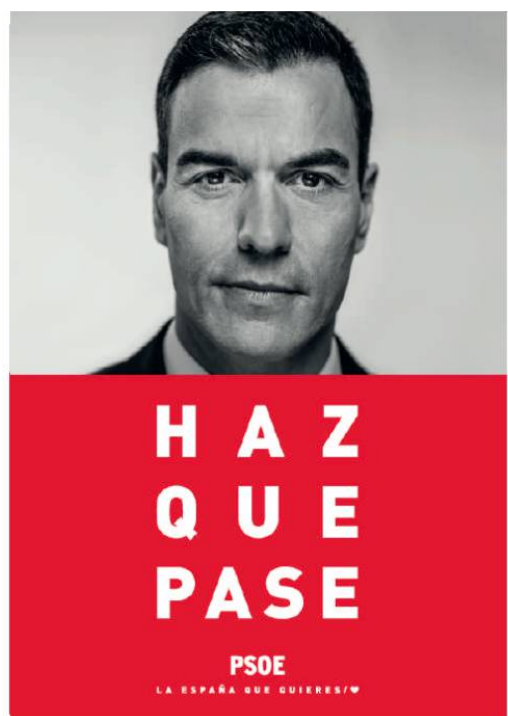

El eslogan es deliberadamente ambiguo y uno de los puntos más criticados por rivales y comentaristas. La combinación de los verbos dejar y pasar, que tienen connotaciones de abandono, pasotismo y desapego ha sido uno de los elementos más utilizados para desmontar el argumentario del partido socialista. El mensaje apela claramente al deseo, la ilusión y los sentimientos en un registro emocional y muy enfocado a un electorado progresista y de tendencia izquierdista a la vez que apuesta por la moderación y el mensaje amable frente a la reinante crispación política de los últimos meses. La tipografía actúa como un bloque alineado y forma un cuadrado perfecto. Trasladan así la idea de solidez y contundencia jugando con el espaciado entre letras.

La opción del blanco y negro está estudiada y responde a la continuidad de una política de comunicación basada en los guiños culturales al cine y a la literatura, que ya utilizó Rodríguez Zapatero en 2015, al cerrar su intervención en el debate electoral frente a Mariano Rajoy con un "Buenas noches y buena suerte"3 la galardonada película que denunciaba los abusos de poder de algunos grupos políticos.

\subsection{Partido popular}

El cartel del Partido Popular da todo el protagonismo y la posición central a su líder Pablo Casado. Un primer plano frontal sobre fondo neutro, claro y liso que destaca más la figura del candidato a la vez que evita cualquier elemento que distraiga la

\footnotetext{
${ }^{3}$ Dirigida por George Clooney en 2005 estuvo nominada a seis óscar, 6 premios Bafta y 4 Globos de oro. El film narra el conflicto históricamente cierto, entre el periodista Edward R. Murrow, presentador de la CBS, y el senador Joseph McCarthy, en los años 50 al inicio del periodismo televisivo. El título hace referencia a la frase que Murrow utilizaba para despedir sus programas.
} 
atención. Un rostro con una amplia sonrisa en la que se muestran los dientes y que connota felicidad y sirve para provocar respuestas positivas en las personas que nos miran. Una sonrisa que intenta parecer natural y sincera pero que muestra cierta tensión en el mentón, fruto de lo artificioso de las sesiones fotográficas a las que deben someterse los políticos antes de las elecciones. Es el único que muestra la corbata de manera clara y presenta una imagen impecable, retocada en exceso y libre de cualquier imperfección en rostro y dientes. Muestra al hijo perfecto, al padre perfecto, al marido perfecto al presidente perfecto, un auténtico valor seguro a pesar de su juventud y falta de experiencia.

Figura 2. Cartel oficial del PP (fuente: PP)

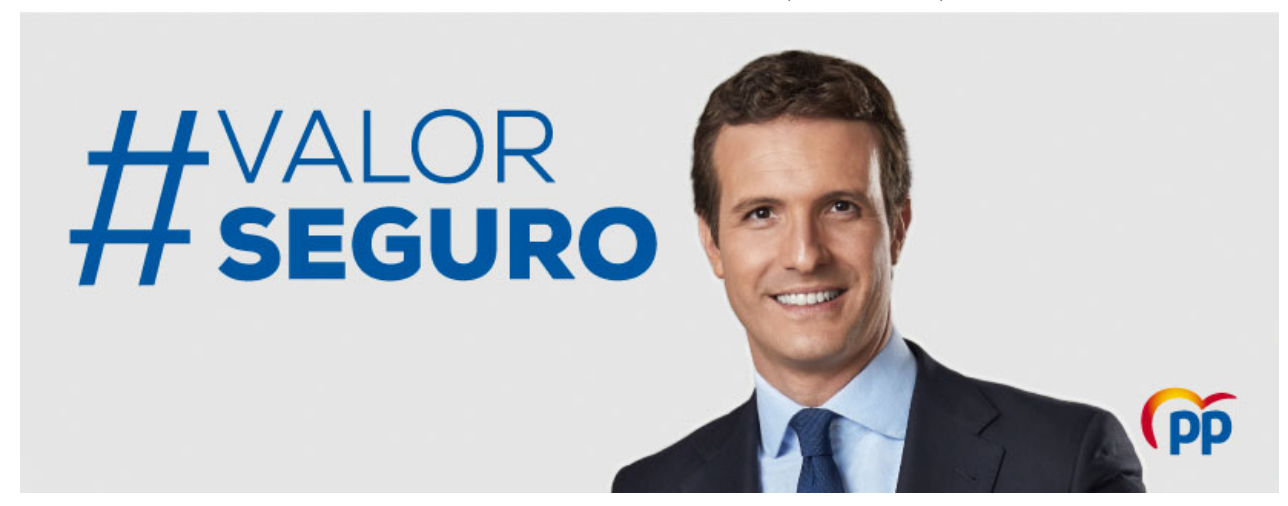

El eslogan es directo, corto y muy conciso, la elipsis verbal y el uso del símbolo hashtag se acerca al electorado más joven y hace un guiño a la nueva forma de comunicarse a través de las redes sociales. Valor nos habla de la economía y de empresa mientras seguro apela al orden, todo corrección, todo de acuerdo a la ley. Se ofrece como la única candidatura libre de riesgos y como la alternativa sin duda al gobierno de Pedro Sánchez y la continuidad de sus políticas. Es una combinación de verbo y adjetivo efectiva y efectista muy en línea con el argumento utilizado que se dirige a los electores descontentos con la labor del gobierno socialista. Frente a la incertidumbre, el descontento y la inestabilidad el PP ofrece el valor seguro de ser un partido con amplia experiencia y trayectoria política reclamando su liderazgo al frente de la oposición.

Es una propuesta gráfica de composición tradicional, conservador y muy en el estilo de los que reclama el votante fiel del partido. Frente a la ambigüedad del PSOE el "valor seguro" del PP. Es un cartel aséptico, carece de elementos emocionales y resulta demasiado frío incluso por la gama de colores utilizados. La única licencia de colores cálidos es el guiño que se produce en su isologotipo donde el símbolo de la gaviota se convierte en una especie de corazón teñido de los colores patrios. Esconde este elemento gráfico una clara alusión a uno de los mensajes emblemáticos del PP, su posición frente al tema del independentismo catalán, pero lo hace de forma sutil y velada. 


\subsection{Ciudadanos}

Es el cartel más cinematográfico e innovador, el más impactante y atractivo por su diseño gráfico y la combinación de elementos. Muestra a su líder, Albert Rivera, avanzando a cámara en un plano americano que recuerda a los pistoleros de las películas del Oeste justo en el momento de máxima acción, el duelo a vida o muerte. Es el más arriesgado y el más atractivo ya que el fondo difuminado de banderas españolas genera cierta ambigüedad y en un primer momento parecen llamas de las que, cual ave Fénix, resurge la figura del político victorioso e indemne tras una explosión. Esa fusión cromática inunda los márgenes del cartel de una potente presencia del naranja característico de la formación política.

El eslogan, breve al igual que la imagen, incita a la acción. Esa apelación directa a los ciudadanos y el uso exclamativo en el verbo hace que en conjunto sea una propuesta, fresca, dinámica y la más original. La comunicación no verbal y la forma de caminar muestran templanza, seguridad y determinación. El rostro no muestra ninguna sonrisa pero si arrojo y firmeza de quien, como el protagonista de una película de acción, no va a detenerse frente a ninguna adversidad.

Figura 3. Cartel oficial de Ciudadanos (fuente: Ciudadanos)

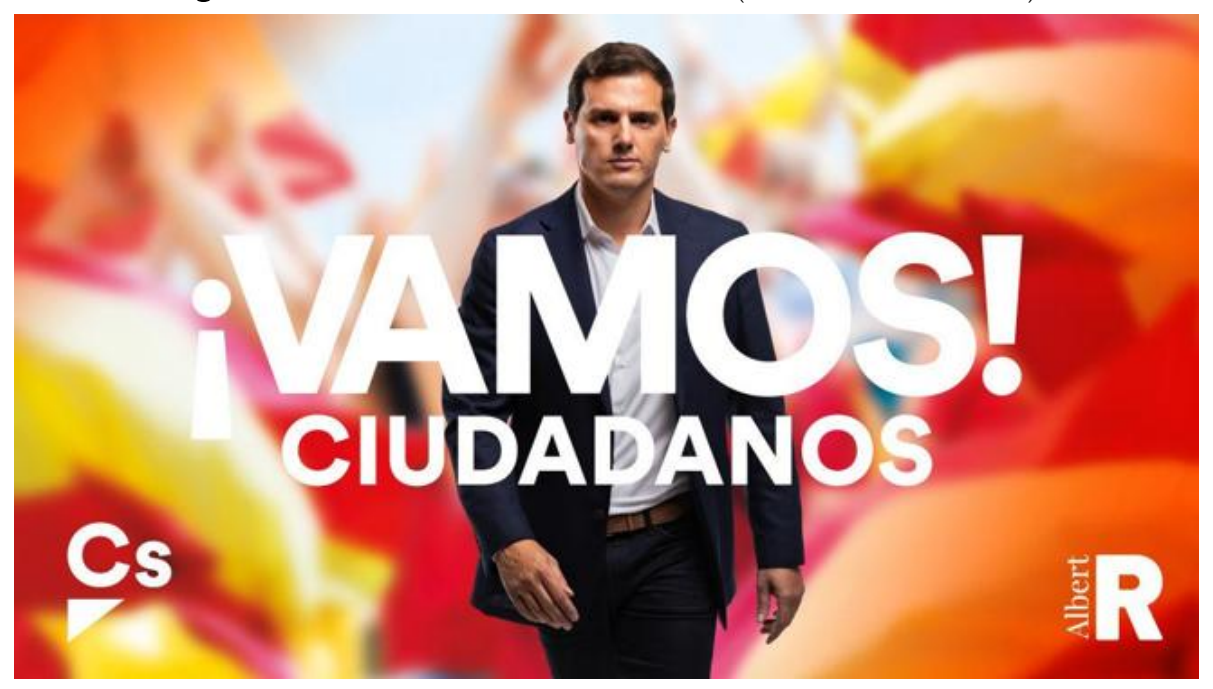

Los elementos de identidad corporativa muestran la evolución de la marca en un claro intento por demostrar modernidad frente al resto de opciones conservadoras con las que compite a la hora de captar votos (PP y Vox) en un claro intento de convertirse en el líder de los partidos del centro-derecha. También en la pegada de carteles se demuestra esa apuesta por la modernidad y la acción y hacen una pegada de carteles digitales con "efectos especiales" incluidos ${ }^{4}$. Todo el acto pone de relieve dos realidades

\footnotetext{
${ }^{4}$ Albert Rivera estaba en Pedraza (Segovia) y proyectó su imagen a la sede del partido en Madrid, eso junto con la pegada de carteles digitales lo convirtió en el partido que más arriesgó y apostó por aunar tecnología e innovación a la vez que mandaba un mensaje por apoyar a las comunidades con más riesgo de despoblación.
} 
que conviven en España, la de la revolución tecnológica que dinamiza las comunicaciones y la de la despoblación rural, representada por la localidad de Pedraza donde se encuentra el candidato durante el arranque de campaña. De esta manera se insiste en una de las ideas de su programa, igualdad de oportunidades para todos los españoles, al margen del lugar en el que vivan.

Es el cartel que mejor sirve para movilizar al electorado y que combina de manera magistral los diferentes recursos gráficos fortaleciendo la imagen corporativa del partido y reforzando la marca personal de su candidato, Albert Rivera al que convierte en una marca nueva apostando por el branding personal y convirtiéndolo en el líder más enérgico y heroico con una estética muy cercana a la de los carteles cinematográficos de películas de acción como La jungla de cristal, Coloso en llamas o los Juegos del hambre.

\subsection{Unidas Podemos}

Pocas semanas antes de la celebración de los comicios, Unidas Podemos fue objeto de duras críticas en la utilización de su cartelería. En concreto, del uso propagandístico que se le dio a la imagen de Pablo Iglesias, de regreso de su permiso de paternidad. Aquel cartel empleaba una imagen del líder de la formación con el eslogan: Ha vuelto. Algunas de las críticas más incisivas provenían del sector más alineado con la lucha feminista del partido, puesto que la persona que había liderado el partido durante la ausencia de Iglesias había sido Irene Montero. Con el fin de evitar más polémicas en este sentido, el cartel prescinde de la imagen de sus líderes y opta por una imagen de un grupo de ciudadanos que levanta las manos pero los rostros que vemos al fondo son de mujer. Esto se entiende como un claro guiño a la decisión del partido de feminizar la lucha política.

Nos ha llamado poderosamente la atención el diseño simétrico del cartel: dos mitades, perfectamente separadas, en las que están representadas el partido y la gente. Desde los orígenes de la formación, uno de sus principios fundamentales ha sido la identificación del partido con las personas. Se ha querido trasladar siempre la idea de que la formación no responde a los mismos principios que los partidos tradicionales y que son las personas, los votantes, los que realmente toman las decisiones. La reescritura del logotipo de fondo, un corazón, uniendo las dos mitades refuerza esta hipótesis. Asimismo, la idea de la elección se ve ensalzada por la presencia de las manos que se levantan. 
Figura 4. Cartel oficial de Unidas Podemos (fuente: Unidas Podemos)

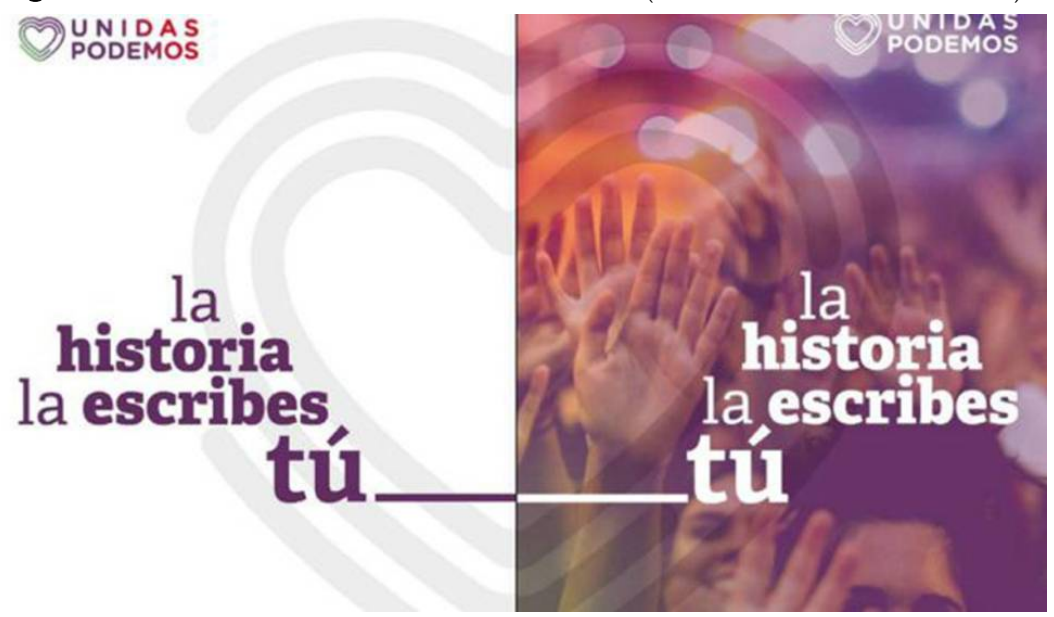

Es significativo también, que la imagen elegida esté desenfocada. Esta decisión puede estar relacionada con el intento de evitar polémicas aludido antes, pero entendemos que responde mejor a la idea de anonimizar a la gente y las personas, que no el pueblo, como el conjunto de la ciudadanía que es la verdadera protagonista de las políticas del partido. Esto se ve reforzado por la presencia del eslogan, "la historia la escribes tú", que definitivamente borra cualquier veleidad de protagonismo que se les pudiera atribuir a los líderes del partido.

Respecto al uso de los colores, los responsables de Unidas Podemos toman la decisión de manejar los que son de uso tradicional en la cartelería electoral por una parte de la izquierda española: el rojo socialista y obrero, el morado feminista y, aunque en menor medida en este caso, el verde del ecologismo. Se trata de una apuesta muy convencional. A este respecto, queremos señalar que no se alude en ningún momento a la concurrencia, en la misma lista de UP, de los candidatos de Izquierda Unida, como sí sucede al revés.

\subsection{Izquierda Unida}

El líder de Izquierda Unidad, Alberto Garzón, concurría como candidato al Congreso de los diputados integrado en las listas de Unidad Podemos. Esta alianza electoral no es nueva en estas las elecciones de 2019 y desde la formación se entiende que no es necesario explicar los detalles a los votantes. Ahora bien, en el caso de IU el cartel tampoco escapó de los análisis críticos. Fue denostado por su planteamiento convencional y por no apostar más que por la imagen del líder de la formación en una fotografía criticada por su falta de actualidad, o falta de atrevimiento en el planteamiento. En ella, vemos a un candidato sonriente inscrito sobre un fondo blanco y gris neutro, que no mira de frente y que va vestido como lo hubieran hecho sus antecesores en las décadas de 1980, o 1990: camisa blanca y chaqueta gris. Se trata de la imagen de un buen chico, jugando con la percepción que los votantes tienen de él. Si bien la imagen proyecta una idea positiva, los elementos que la componen contrastan también con lo 
que significa la presencia de Garzón al frente de la formación, en tanto que renovación y rejuvenecimiento del partido.

Figura 5. Cartel oficial de Izquierda Unida (fuente: Izquierda Unida)

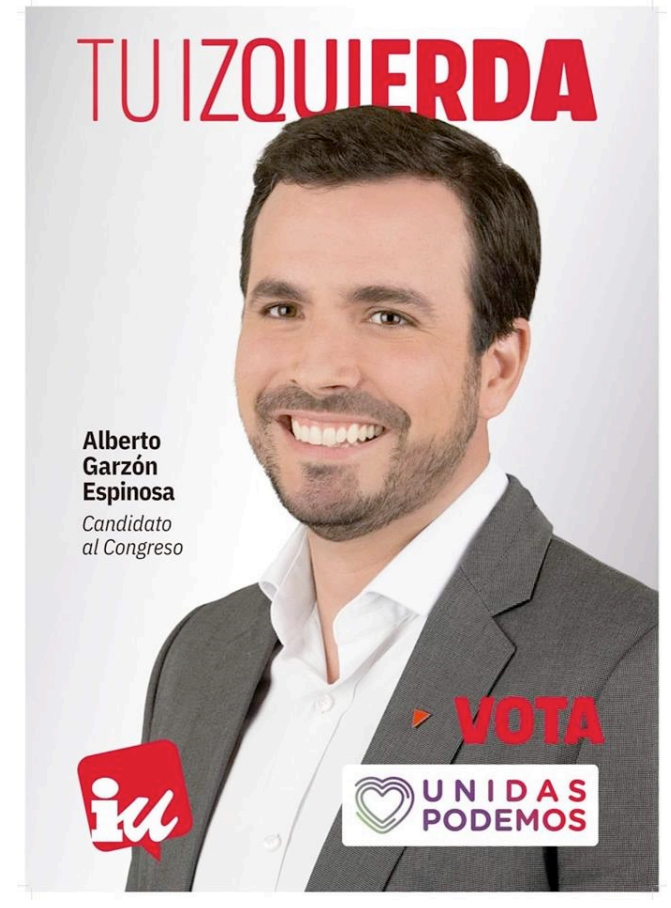

El eslogan de campaña, Tu Izquierda, destaca en lo alto de la imagen. Los responsables del mismo deciden presentarlo en un degradado que refuerza el trazo a medida que lo leemos. Esta decisión incide en la idea de que IU y UP son la verdadera opción de izquierdas del país. Resulta significativo el uso, casi en exclusiva en todo el cartel, del color rojo en el eslogan. Se trata del mismo rojo presente en el logotipo de la formación. No obstante, se nos antoja muy parecido al del propio PSOE, que también utiliza el rojo de manera profusa en su cartel.

Es un elemento tradicional en los carteles de la formación el hecho de que se usen muchas y diferentes tipografías. Esta profusión de diferentes estilos no es positiva para la correcta percepción del mensaje que transmite. Esta idea se ve reforzada por el hecho de que el cartel y el candidato, en realidad, piden el voto para Unidas Podemos. Entendemos que, con el fin de no remarcar demasiado la asimilación de IU dentro de la formación de Pablo Iglesias, se iguala en el diseño del cartel el tamaño y proporción de los dos logotipos. No obstante, como decíamos, entendemos que esto conduce más a una lectura confusa del mismo.

\subsection{VOX}

Cargado de simbología épica, lo primero que llama la atención del cartel elegido por Vox es la repetición de elementos. En primer lugar, el nombre del partido aparece 3 
veces al igual que la palabra España, a la vez que su presencia se refuerza por la utilización de la combinación rojigualda. Pero sin duda la redundancia más exagerada aparece en el diseño y en los elementos de la composición gráfica donde encontramos hasta 5 banderas, mandando un claro mensaje con el que será uno de sus lemas de campaña defender a España de todos los peligros que la acechan. Para recalcar esa misión de salvaguardia de la unidad del territorio y sin ningún complejo, a pesar de su corta trayectoria política, su líder posa en un primer plano de perfil que recuerda a las efigies utilizadas en numástica por los jefes de estado y monarcas. Su mirada hacia el horizonte, hacia el futuro y hacia un auditorio al que no se ve pero se intuye crea una correspondencia casi perfecta entre el final de su barba y su mentón con la $\vee$ de Vox que vemos al fondo y que remarca esa voz que se proyecta al micrófono. Igualmente importante es la exagerada utilización de los elementos de identidad corporativa para hacerse oír y ser la voz de quienes han estado, en su opinión, silenciados y como recuerda su eslogan, van a votar por España.

El propio nombre del partido es en sí mismo un acierto desde el punto de vista de la creación de marca y la identidad corporativa. Es sencillo, directo, fácil de recordar y muy alegórico. No es unas siglas, ni una palabra en castellano sino un término procedente del latín que se traduce literalmente por voz. De ahí la importancia de la selección de la imagen, su líder frente al micrófono que va a permitir que su mensaje se difunda y llegue a todos los rincones. La elección y combinación de los colores no es casual. Por una parte, el cartel se divide de forma simétrica en dos banderas que actúan cual positivo-negativo y juegan a ser una bandera que ondea al aire con los colores corporativos de Vox que aquí recuerdan a la bandera Andaluza primer territorio, electoralmente hablando, ganado. El espacio ocupado por cada una de las franjas coincide en grosor con el doble ancho de la banda amarilla central de la bandera patria y además al darle efecto de movimiento simula ondear al viento.

Figura 6. Cartel oficial de VOX (fuente: VOX)

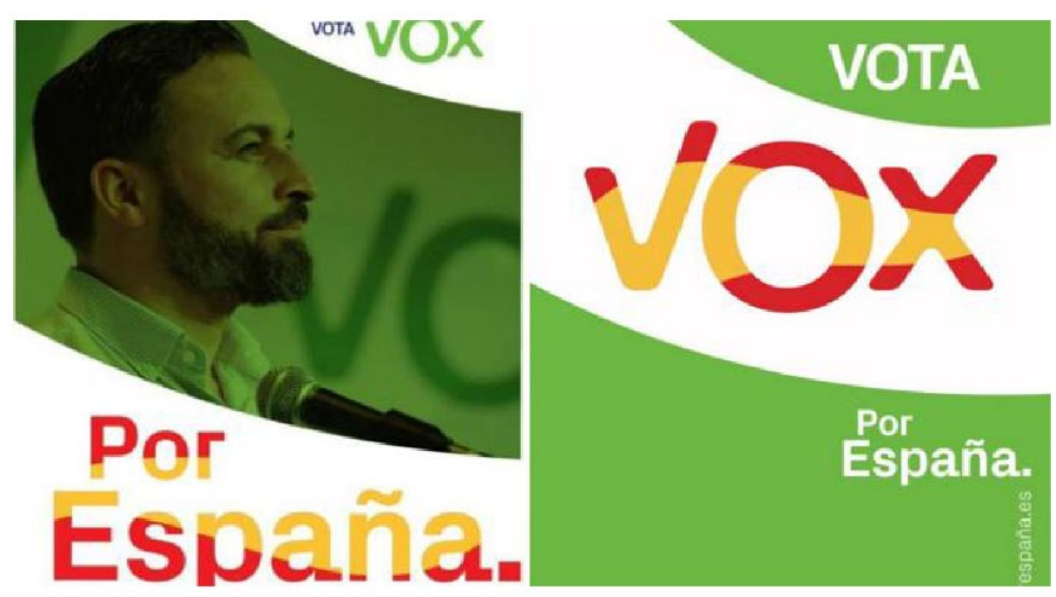


La tipografía utilizada también esconde sutiles mensajes. En el caso de las mayúsculas que forman el nombre del partido la primera y la última son claramente asimétricas y destacan la trayectoria al alza del partido arropado por un electorado cada vez más numeroso. De ahí que la $\vee$ simule ser un vector de aspa como los utilizados para marcar la respuesta correcta, los aciertos, también en color verde, frente al resto de opciones (partidos rivales) que son la opción errónea. Esa asimetría de derecha a izquierda en ambos casos representa un avance a la vez que parece simbolizar que España ha tocado fondo y necesita un líder como Santiago Abascal que ayude a todos los votantes de la derecha más conservadora a alzar su voz por España. La combinación cromática utilizada es caótica y excesiva por la abundancia de colores y la falta de complementariedad de muchos de ellos. Predomina de forma clara el verde corporativo que simboliza el ecologismo y hace un guiño a su anterior campaña de las elecciones andaluzas con Santiago Abascal cabalgando por una verde pradera.

El eslogan encierra la esencia de su estrategia de comunicación y ante la opacidad de su programa, lo que no deja lugar a dudas es su apuesta de pedir el voto por España. Incluso lo remarca incluyendo un punto final tras el eslogan, lo cual es significativo por lo poco habitual en publicidad de este recurso y por la rotundidad que le da al mensaje. España y nada más, eso es lo importante ahora.

Tabla 1. Análisis multimodal de los carteles (fuente: elaboración propia)

\begin{tabular}{|c|c|c|c|c|c|c|}
\hline $\begin{array}{c}\text { CARTEL } \\
\text { ELECTORAL }\end{array}$ & PSOE & $\begin{array}{l}\text { PARTIDO } \\
\text { POPULAR }\end{array}$ & CIUDADANOS & $\begin{array}{l}\text { UNIDAS } \\
\text { PODEMOS }\end{array}$ & $\begin{array}{c}\text { IZQUIERDA } \\
\text { UNIDA }\end{array}$ & VOX \\
\hline $\begin{array}{l}\text { Imagen } \\
\text { utilizada }\end{array}$ & $\begin{array}{l}\text { PPP de } \\
\text { Pedro } \\
\text { Sánchez } \\
\text { sobre } \\
\text { fondo gris. }\end{array}$ & $\begin{array}{l}\text { PP Pablo } \\
\text { Casado } \\
\text { sobre } \\
\text { fondo claro. }\end{array}$ & $\begin{array}{l}\text { PAC Albert } \\
\text { Rivera. } \\
\text { Fondo banderas } \\
\text { España } \\
\text { difuminadas. }\end{array}$ & $\begin{array}{l}\text { PM de un grupo } \\
\text { de personas } \\
\text { levantando las } \\
\text { manos sobre un } \\
\text { fondo } \\
\text { difuminado. }\end{array}$ & $\begin{array}{l}\text { PP de } \\
\text { Alberto } \\
\text { Garzón } \\
\text { sobre un } \\
\text { fondo } \\
\text { neutro. }\end{array}$ & $\begin{array}{l}\text { PP de } \\
\text { Santiago } \\
\text { Abascal de } \\
\text { perfil junto a } \\
\text { micrófono. } \\
\text { Fondo } \\
\text { logotipo } \\
\text { VOX } \\
\end{array}$ \\
\hline Eslogan & $\begin{array}{l}\text { Haz que } \\
\text { pase. La } \\
\text { España que } \\
\text { quieres }\end{array}$ & $\begin{array}{l}\text { Valor } \\
\text { seguro }\end{array}$ & $\begin{array}{l}\text { ¡Vamos! } \\
\text { Ciudadanos }\end{array}$ & $\begin{array}{l}\text { La historia la } \\
\text { escribes tú }\end{array}$ & Tu Izquierda & Por España. \\
\hline Formato & Vertical & $\begin{array}{l}\text { Vertical y } \\
\text { horizontal }\end{array}$ & $\begin{array}{l}\text { Vertical } \\
\text { Formato papel } \\
\text { y digital (3D) } \\
\text { para arranque } \\
\text { de campaña. }\end{array}$ & Horizontal & Vertical & Horizontal \\
\hline Tipografía & $\begin{array}{l}\text { De caja alta } \\
\text { y de palo } \\
\text { seco. }\end{array}$ & $\begin{array}{l}\text { De caja alta } \\
\text { y de palo } \\
\text { seco. } \\
\text { Diferentes } \\
\text { grosores. } \\
\text { Destaca la } \\
\text { negrita de } \\
\text { SEGURO. }\end{array}$ & $\begin{array}{l}\text { Versátil sans } \\
\text { serif, una familia } \\
\text { sencilla, limpia y } \\
\text { directa }\end{array}$ & $\begin{array}{l}\text { Dos tipologías: } \\
\text { una mayúscula } \\
\text { de palo seco } \\
\text { que acompaña } \\
\text { el logotipo de la } \\
\text { formación. Una } \\
\text { minúscula estilo } \\
\text { TNR }\end{array}$ & $\begin{array}{l}\text { Al menos } \\
\text { cuatro: Dos } \\
\text { de palo seco } \\
\text { para el } \\
\text { eslogan y } \\
\text { logotipo de } \\
\text { Unidas } \\
\text { Podemos. } \\
\text { Otras dos } \\
\text { con serifa en } \\
\text { minúsculas } \\
\text { para el texto } \\
\text { con el }\end{array}$ & $\begin{array}{l}\text { Mayúsculas y } \\
\text { minúsculas. } \\
\text { Destaca la } \\
\text { asimetría de } \\
\text { las letras de } \\
\text { Vox. La R } \\
\text { está retocada } \\
\text { y parece un } \\
25 \% \text { de una } \\
\text { esvástica. }\end{array}$ \\
\hline
\end{tabular}




\begin{tabular}{|c|c|c|c|c|c|c|}
\hline & & & & & $\begin{array}{l}\text { nombre del } \\
\text { candidato y } \\
\text { el logotipo } \\
\text { de IU }\end{array}$ & \\
\hline Colorimetría & $\begin{array}{l}\text { Blanco y } \\
\text { negro. } \\
\text { Rojo }\end{array}$ & $\begin{array}{l}\text { Azul, } \\
\text { blanco, } \\
\text { negro, rojo } \\
\text { y amarillo }\end{array}$ & $\begin{array}{l}\text { Naranja, rojo, } \\
\text { amarillo, blanco } \\
\text { y negro }\end{array}$ & $\begin{array}{l}\text { Morado, blanco, } \\
\text { rojo anaranjado } \\
\text { y verde }\end{array}$ & $\begin{array}{l}\text { Blanco, gris } \\
\text { y rojo. } \\
\text { Aparecen el } \\
\text { verde y el } \\
\text { morado en } \\
\text { el logotipo } \\
\text { de Unidas } \\
\text { Podemos } \\
\end{array}$ & $\begin{array}{l}\text { Verde, } \\
\text { Blanco, } \\
\text { Rojo, } \\
\text { Amarillo, } \\
\text { azul. } \\
\text { Sobrecargado } \\
\text { y excesivo }\end{array}$ \\
\hline $\begin{array}{l}\text { Elementos } \\
\text { semióticos }\end{array}$ & $\begin{array}{l}\text { Omisión de } \\
\text { la corbata. } \\
\text { Corazón } \\
\text { rojo, } \\
\text { símbolo de } \\
\text { emoción, } \\
\text { pasión, el } \\
\text { órgano } \\
\text { motor, }\end{array}$ & $\begin{array}{l}\text { Gaviota- } \\
\text { corazón } \\
\text { Hashtags } \\
\text { para } \\
\text { trasmitir } \\
\text { modernidad } \\
\text { y acercarse } \\
\text { al } \\
\text { electorado } \\
\text { más joven. }\end{array}$ & $\begin{array}{l}\text { Triángulo } \\
\text { evolución de su } \\
\text { antigua } \\
\text { identidad } \\
\text { corporativa } \\
\text { cuyo "bocadillo" } \\
\text { es símbolo de } \\
\text { diálogo. }\end{array}$ & $\begin{array}{l}\text { El conjunto de } \\
\text { manos unidas. El } \\
\text { cartel se } \\
\text { presenta de } \\
\text { forma simétrica: } \\
\text { el grupo y la } \\
\text { formación } \\
\text { política. Da a } \\
\text { entender que la } \\
\text { formación y “la } \\
\text { gente” son la } \\
\text { misma cosa. }\end{array}$ & $\begin{array}{l}\text { Es un cartel } \\
\text { muy } \\
\text { tradicional } \\
\text { en su } \\
\text { concepto. } \\
\text { No incluye } \\
\text { elementos } \\
\text { obvios de } \\
\text { diseño. La } \\
\text { lectura } \\
\text { semiótica } \\
\text { debe } \\
\text { hacerse } \\
\text { sobre el } \\
\text { propio } \\
\text { candidato: } \\
\text { barba, } \\
\text { amplia } \\
\text { sonrisa, } \\
\text { vestido con } \\
\text { camisa y } \\
\text { chaqueta, } \\
\text { pero sin } \\
\text { corbata. }\end{array}$ & $\begin{array}{l}\text { Banderas (5) } \\
\text { que ondean } \\
\text { al aire, } \\
\text { Micrófono } \\
\text { para hacerse } \\
\text { oír, } \\
\text { Barbilla y } \\
\text { mandíbula } \\
\text { perfilada de } \\
\text { la que sale el } \\
\text { El punto que } \\
\text { cierra el } \\
\text { eslogan lo } \\
\text { complementa } \\
\text { Por España. } \\
\text { (y punto) } \\
\text { Mirada } \\
\text { perdida al } \\
\text { horizonte } \\
\text { que simboliza } \\
\text { el futuro con } \\
\text { una clara } \\
\text { intención de } \\
\text { continuidad }\end{array}$ \\
\hline $\begin{array}{l}\text { Identidad } \\
\text { corporativa }\end{array}$ & $\begin{array}{l}\text { Color rojo } \\
\text { corporativo } \\
\text { que } \\
\text { identifica a } \\
\text { los } \\
\text { votantes } \\
\text { socialistas }\end{array}$ & $\begin{array}{l}\text { Isologotipo } \\
\text { completo } \\
\text { pero donde } \\
\text { la gaviota se } \\
\text { convierte } \\
\text { en un } \\
\text { corazón } \\
\text { bandera. } \\
\text { Color azul } \\
\text { corporativo } \\
\text { tipografía y } \\
\text { corbata }\end{array}$ & $\begin{array}{l}2 \text { logotipos el } \\
\text { de Ciudadanos } \\
\text { y una marca } \\
\text { personal Albert } \\
\text { R. } \\
\text { Modernizada y } \\
\text { actualizada. }\end{array}$ & $\begin{array}{l}\text { Aparece el } \\
\text { logotipo de } \\
\text { Unidas } \\
\text { Podemos en los } \\
\text { tres colores que } \\
\text { definen } \\
\text { tradicionalmente } \\
\text { a una parte de } \\
\text { la izquierda } \\
\text { española: rojo, } \\
\text { morado y verde }\end{array}$ & $\begin{array}{l}\text { Aparecen } \\
\text { los logotipos } \\
\text { de Unidas } \\
\text { Podemos y } \\
\text { de Izquierda } \\
\text { Unida. }\end{array}$ & $\begin{array}{l}\text { Logotipo (3 } \\
\text { veces) } \\
\text { Colores } \\
\text { corporativos. }\end{array}$ \\
\hline
\end{tabular}

\section{DISCUSIÓN Y CONCLUSIONES}

Tras analizar las diferentes propuestas gráficas de los principales partidos políticos que concurren a las elecciones generales de 2019, y que obtuvieron mayor representación parlamentaria tras los comicios, extraemos una serie de conclusiones que se derivan tanto del tratamiento gráfico como de la utilización de recursos comunicativos:

- Ciudadanos y Vox son los partidos que presentan las opciones más atractivas llamativas por su diseño y, en este sentido, las más arriesgadas. Ambos presentan a sus líderes como "salvadores" de una España que en el caso de Ciudadanos parece en llamas. 
- El Partido Popular hace la propuesta más aséptica y conservadora, la menos arriesgada, con el permiso de IU, y presenta a su candidato como un buen aspirante a un proceso de selección de personal para reformar su eslogan de valor seguro.

- Podemos otorga todo el protagonismo al votante y prescinde de la foto de su candidato a la presidencia, Pablo Iglesias, ni de ningún otro líder. Se toma esta decisión para evitar más desgaste mediático y volver a sus orígenes centrados en sus bases.

- Los tres partidos que se dirigen al votante de la derecha incluyen en sus carteles la bandera española. Tras años de ausencia en la cartelería de este elemento se recupera ante la amenaza del independentismo catalán. Es un claro posicionamiento político y una declaración de intenciones en la defensa de la unidad de España.

- Se utiliza el corazón como elemento connotativo para conectar emocionalmente con el electorado y aparece en las propuestas gráficas del PSOE, PP y Unidas Podemos. Pero la significación es diferente mientras en partido socialista con el uso del rojo corporativo lo relaciona con el amor al partido y se dirige al electorado "rojo, el Partido Popular lo convierte en una bandera española y Unidas Podemos en el órgano central simbolizado por las asambleas de sus bases.

- Finalmente, la propuesta de Izquierda Unida es deudora de su papel "subalterno" respecto a la candidatura de Unidas Podemos. Esta dependencia limita el poder del cartel, que además no destaca en ningún aspecto de su diseño, resultando en una propuesta muy conservadora y convencional e incluso desfasada.

La cartelería electoral ha recuperado parte del protagonismo perdido desde la recuperación de la democracia en España. En líneas generales, en un contexto de menor complejidad tecnológica en relación con la comunicación, el cartel electoral cumplía un papel, en el sentido literal, de presentación de los candidatos. El papel permitía a todas las formaciones políticas llegar donde no lo hacía la televisión. En el momento presente, tal y como hemos tratado de demostrar, su función es la de reforzar la estrategia de los partidos en la construcción de sus candidatos-marca.

Los carteles analizados representan los valores comunicativos de cada partido. Reúnen en su configuración, aquellos elementos que resumen las principales propuestas políticas de cada formación. Debemos destacar, que el cartel, en realidad, ejerce una función de refuerzo del trabajo y gestión comunicativa que los partidos hacen en otros ámbitos. A este respecto, con un mayor o menor grado de acierto, los seis ejemplos elegidos cumplen con esta función.

\section{RECONOCIMIENTOS}

Este artículo forma parte de los trabajos desarrollados en el seno de "DEBATv, Debates Electorales Televisados en España: Modelos, Proceso, Diagnóstico y Propuesta" (CSO2017-83159-R) proyecto de I+D+I (Retos) financiado por el Ministerio de Ciencia, Innovación y Universidades y la Agencia Estatal de Investigación (AEI) del Gobierno de 
España, con el apoyo del Fondo Europeo de Desarrollo Regional (FEDER) de la Unión Europea

\section{REFERENCIAS BIBLIOGRÁFICAS}

Capriotti, P. (2013). Planificación estratégica de la Imagen Corporativa. Málaga: Instituto de Investigación en Relaciones Públicas.

Cárcamo Morales, B. (2018). El análisis del discurso multimodal: una comparación de propuestas metodológicas. Forma y Función, 31(2), 145-174.

Delli Caprini, M., \& Williams, B. A. (2011). After broadcasting news. Nueva York: Cambridge.

Esquivel, D. (2019). Carteles electorales en la campaña 2019 en España. En Psicología para cambiar la política. Recuperado de: https://maquiaveloyfreud.com/carteleselectorales-campana-2019-espana

Kress, G., \& Van Leeuwen, T. (2006). Reading Images: The Grammar of Visual Design. Londres: Routledge.

Hood, R. (2014). Presencia y actividad de los miembros del Consejo Superior de Investigaciones Científicas en ResearchGate y Academia.edu. Gallaecia, 6, 214-305. DOI: https://doi.org/10.1177/0093650214534963

Pena Álvarez, P. (2014). Las redes sociales como factor diferencial en el periodismo asiático. En S. Direito (Coord.), De los medios a los metamedios (pp. 104-163). Santiago: lacobus.

Peris-Blanes, À., \& Llorca-Abad, G. (2018). Los nuevos formatos audiovisuales en la comunicación política: redes sociales y entretenimiento televisivo. En A. Larrondo Ureta [Coord.]. Claves del periodismo político y la comunicación estratégica en el escenario comunicativo convergente (pp. 323-361). Bilbao: Universidad del País Vasco.

Richards, B. (2010). News and the emotional public sphere. En S. Allan [Ed.]. The Routledge Companion to News and Journalism. (pp. 301-311). New York: Routledge.

Ries, A., \& Trout, J. (2002). Posicionamiento: la batalla por su mente. México: McGraw Hill.

Rodríguez Freire, J. (2001). El conflicto de los derechos audiovisuales en las retransmisiones deportivas en radio. El caso de la Liga de Fútbol Profesional. Vigo: Universidad de Vigo. 
Seijo Romero, S., Pita Lois, L. D., \& Bernáldez Figueroa, R. (2012). Comunicación institucional en la administración autonómica española. Orbis, 20, 168-181. Recuperado de: https://www.revistalatinacs.org/071/paper/1094/14es.html

Silvosa, N. (2018, julio 22). Treinta y tres titulaciones gallegas, en el ránking de las 500 mejores del mundo. La Voz de Galicia, p. 3. Recuperado de: https://www.lavozdegalicia.es/noticia/galicia/2018/07/22/treinta-tres-titulacionesgallegas-ranking-500-mejores-mundomas-1200-universidadesseleccionadas/0003_201807G22P11992.htm

La Vanguardia, (12/04/2019) Los carteles Ikea. Recuperado de: https://www.lavanguardia.com/politica/20190412/461598426210/elecciones-generalesespana-2019-carteles-electorales-psoe-pp-ciudadanos-podemos-vox.html

Vico, M. E., \& Lepe, J. C. (2019). El género del cartel político: sus principales características. Brazilian Journal of Information Design, vol. 16, núm. 2, 296-308. 